\title{
Kinetic Studies on Transesterification Reactions between Poly (EthyleneTerephthalate) and Poly(Ethylene Sebacate)
}

\author{
Masao Murano and Reizo Yamadera* \\ Textile Research Institute, Toyobo Co. Ltd., Katata, Otsu, Japan. \\ (Received May 11, 1970)
}

\begin{abstract}
The kinetics of the transesterification reaction between PET and PES was studied with data obtained by NMR spectra. Assuming a second-order reaction, the rate constant $k$ takes an almost constant value over-all samples having different feed ratios, except during the initial stages of the reaction. This demonstrates that the transesterification reaction is second-order. (The concentration of catalyst is constant.)

KEY WORDS NMR/Transesterification Reaction/Poly (Ethylene Terephthalate)/Poly(Ethylene Sebacate)/Second-Order Reaction/Rate Constants/
\end{abstract}

In our previous paper, ${ }^{1}$ various kinds of copolyesters were studied by means of an NMR spectrometer and the average sequence length and sequence distribution of structural units were determined. Transesterification reactions between two types of homopolyesters were also followed by NMR spectroscopy and it was found that random copolyesters were formed by ordinary molten-state copolycondensation and also during the transesterification reaction between the two kinds of homopolyesters.

The kinetics of catalytic transesterification has received the attention of many investigators, but even in respect of the order of the reaction little agreement has been reached. Polycondensation kinetics was first studied by Skwarski ${ }^{2}$ who found it to be third-order. Griehl and Schnock $^{3}$ investigated the kinetics of polycondensation reactions and found it to be firstorder (with respect to ester group alone). Challa ${ }^{4}$ studied the polycondensation reaction and assessed it a second-order mechanism. Fontana ${ }^{5}$ found that the kinetic data fit a third-order reaction for the transesterification: one order each with respect to the hydroxyl group, methoxyl group, and catalyst. The kinetics of the transesterification reaction, therefore, seems to be quite complicated.

In the present paper, the kinetics of transesterification reactions between poly(ethylene

\footnotetext{
* Present address: Iwakuni Plant, Toyobo Co.
} Ltd., Iwakuni, Yamaguchi, Japan. terephthalate) and poly (ethylene sebacate) was studied and the rate constants in this reaction were determined by using the data obtained from NMR spectra.

\section{EXPERIMENTAL}

Poly(ethylene terephthalate), PET,

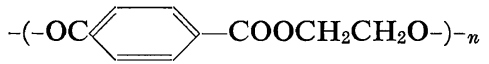

and poly(ethylene sebacate), PES, $-\left(-\mathrm{OCCH}_{2}-\right.$ $\left.\mathrm{CH}_{2} \mathrm{CH}_{2} \mathrm{CH}_{2} \mathrm{CH}_{2} \mathrm{CH}_{2} \mathrm{CH}_{2} \mathrm{CH}_{2} \mathrm{COOCH}_{2} \mathrm{CH}_{2} \mathrm{O}_{-}\right)_{n}$ were prepared from glycols and dimethyl esters of the acids by ordinary molten-state polycondensation under reduced pressure, using $\mathrm{Sb}_{2} \mathrm{O}_{3}(5 \times$ $\left.10^{-4} \mathrm{~mol} \%\right)$ and $\mathrm{Zn}(\mathrm{OAC})_{2} \cdot 2 \mathrm{H}_{2} \mathrm{O}\left(1 \times 10^{-3} \mathrm{~mol} \%\right)$ as catalysts.

PET and PES were mixed in various proportions and stirred under nitrogen atmosphere at $276^{\circ} \mathrm{C}$ for several minutes to enable the transesterification reaction to be carried out.

The NMR spectra of the resultant copolymers were measured in trifluoroacetic acid solution $(0.05 \mathrm{~g} / \mathrm{m} l)$ at $70^{\circ} \mathrm{C}$ with Varian A-60 and HA100 spectrometers.

\section{RESULTS AND DISCUSSION}

The mechanism of the transesterification reaction comprises three processes:

(a)

$$
\begin{aligned}
& \sim \mathbf{T}-\mathrm{T}-\mathrm{OH}+\cdots \mathrm{S}-\mathrm{S}-\mathrm{OH} \rightleftarrows \\
& \sim \mathrm{T}-\mathrm{S} \sim \mathrm{EG}
\end{aligned}
$$


Transesterification between PET and PES

Table I. Changes in sequence distributions during transesterification between PET and PES at various feed ratios

\begin{tabular}{|c|c|c|c|c|}
\hline PET/PES & $\begin{array}{c}\text { Time, } \\
\text { min }\end{array}$ & $S-G-S$ & $\mathrm{~T}-\mathrm{G}-\mathrm{S}$ & $T-G-T$ \\
\hline \multirow[t]{5}{*}{$9 / 1$} & 10 & $7.51 \%$ & $4.37 \%$ & $88.12 \%$ \\
\hline & 30 & 5.14 & 10.28 & 84.58 \\
\hline & 60 & 3.08 & 14.42 & 82.50 \\
\hline & 120 & 2.11 & 19.53 & 78.36 \\
\hline & 180 & 1.93 & 19.90 & 78.17 \\
\hline \multirow[t]{5}{*}{$8 / 2$} & 10 & 16.40 & 8.00 & 75.60 \\
\hline & 30 & 9.75 & 18.85 & 71.39 \\
\hline & 60 & 7.31 & 25.13 & 67.56 \\
\hline & 120 & 6.60 & 27.75 & 65.65 \\
\hline & 180 & 4.99 & 29.49 & 65.52 \\
\hline \multirow[t]{5}{*}{$7 / 3$} & 10 & 27.09 & 7.60 & 65.31 \\
\hline & 30 & 18.55 & 20.47 & 60.98 \\
\hline & 60 & 16.22 & 28.91 & 54.87 \\
\hline & 120 & 12.22 & 36.52 & 51.26 \\
\hline & 180 & 9.97 & 38.46 & 51.57 \\
\hline \multirow[t]{5}{*}{$6 / 4$} & 10 & 36.03 & 8.39 & 55.58 \\
\hline & 30 & 28.29 & 24.16 & 47.55 \\
\hline & 60 & 20.75 & 36.64 & 42.61 \\
\hline & 120 & 19.13 & 40.45 & 40.42 \\
\hline & 180 & 18.97 & 42.36 & 38.67 \\
\hline \multirow[t]{5}{*}{$5 / 5$} & 10 & 45.83 & 9.27 & 44.90 \\
\hline & 30 & 36.06 & 28.62 & 35.32 \\
\hline & 60 & 30.53 & 40.04 & 29.43 \\
\hline & 120 & 27.85 & 45.57 & 26.58 \\
\hline & 180 & 26.00 & 47.20 & 26.80 \\
\hline \multirow{5}{*}{$4 / 6$} & 10 & 53.90 & 9.44 & 36.66 \\
\hline & 30 & 45.50 & 26.63 & 27.87 \\
\hline & 60 & 40.09 & 36.77 & 23.14 \\
\hline & 120 & 38.04 & 40.38 & 21.58 \\
\hline & 180 & 37.13 & 42.40 & 20.47 \\
\hline \multirow[t]{5}{*}{$3 / 7$} & 10 & 64.98 & 7.64 & 27.38 \\
\hline & 30 & 58.62 & 21.32 & 20.06 \\
\hline & 60 & 53.50 & 29.82 & 16.68 \\
\hline & 120 & 50.25 & 38.04 & 11.71 \\
\hline & 180 & 50.35 & 38.50 & 11.15 \\
\hline \multirow[t]{5}{*}{$2 / 8$} & 10 & 76.68 & 8.27 & 15.05 \\
\hline & 30 & 71.60 & 18.96 & 9.44 \\
\hline & 60 & 65.67 & 26.21 & 8.12 \\
\hline & 120 & 66.10 & 28.59 & 5.31 \\
\hline & 180 & 65.51 & 29.28 & 5.21 \\
\hline \multirow[t]{5}{*}{$1 / 9$} & 10 & 88.38 & 4.55 & 7.07 \\
\hline & 30 & 83.06 & 11.76 & 5.18 \\
\hline & 60 & 81.31 & 14.50 & 4.19 \\
\hline & 120 & 79.00 & 19.69 & 1.31 \\
\hline & 180 & 79.19 & 19.90 & 0.91 \\
\hline
\end{tabular}

(b)

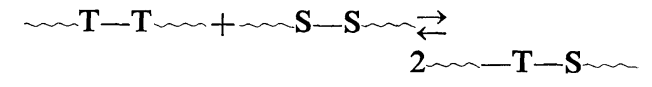

(c) $\sim \mathbf{T}-\mathbf{T}-\mathrm{OH}+\cdots \mathbf{S}-\mathbf{S} \sim \rightleftarrows$ $\underset{\sim \mathrm{S}-\mathrm{S}-\mathrm{OH}+\sim \mathbf{T}-\mathbf{T} \sim \mathrm{S}-\mathrm{S}}{\sim \mathrm{S}-\mathrm{T} \sim+\cdots \mathrm{T}-\mathrm{T}-\mathrm{OH}}$

Reaction (a), which proceeds by ester interchange between the hydroxyl group of a 2hydroxyethyl ester end group and the ester linkage of another 2-hydroxyethyl ester end group, links the ends of two chain molecules by elimination of ethylene glycol. This reaction is extremely small in this experiment under ordinary pressure.

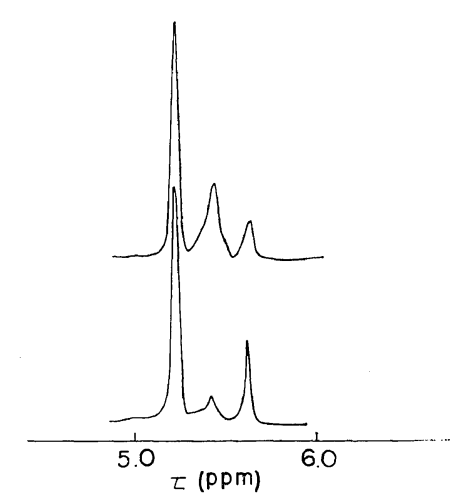

(a)

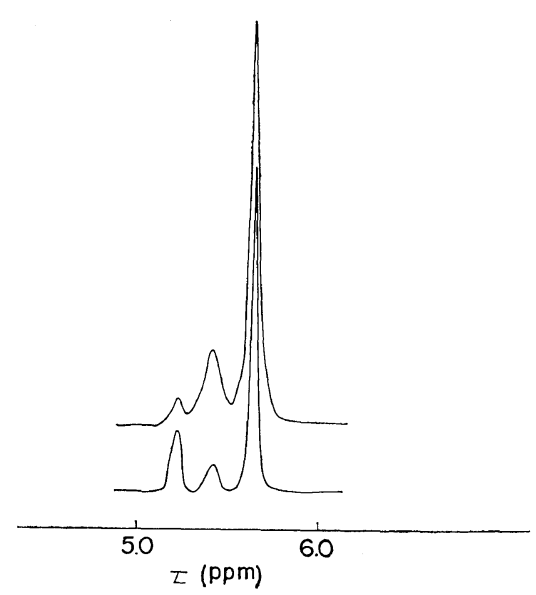

(b)

Figure 1. $60 \mathrm{MHz}$ ethylene glycol proton resonance spectra of transesterified polymers of PETPES ((a) $8 / 2$ and (b) $2 / 8$ ) in chloroform at $70^{\circ} \mathrm{C}$. upper: 180 -min transesterification. lower: 10-min transesterification. 
Reaction (b) proceeds by ester-ester interchange between two ethylene diester groups situated along the PET and PES polymer chains.

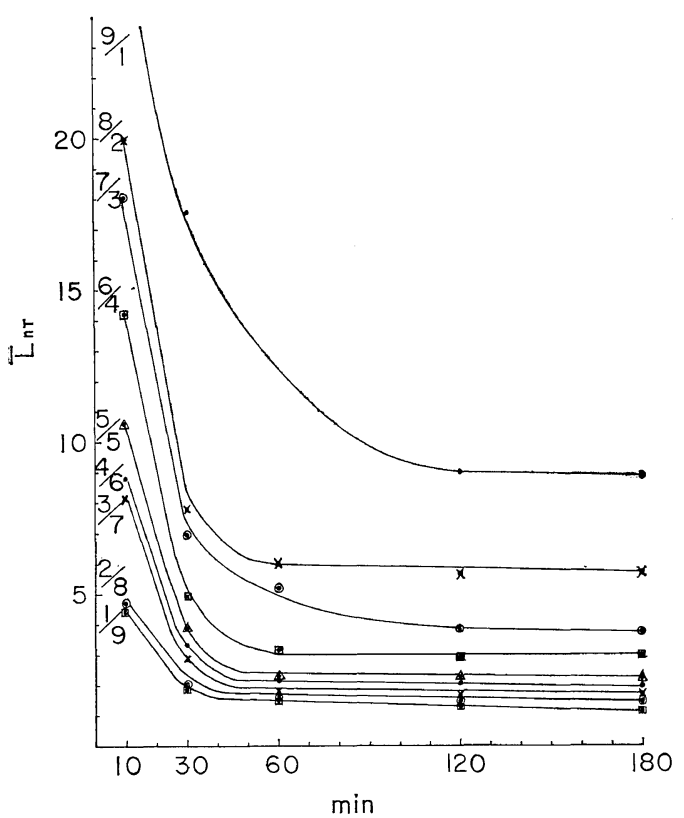

(a)

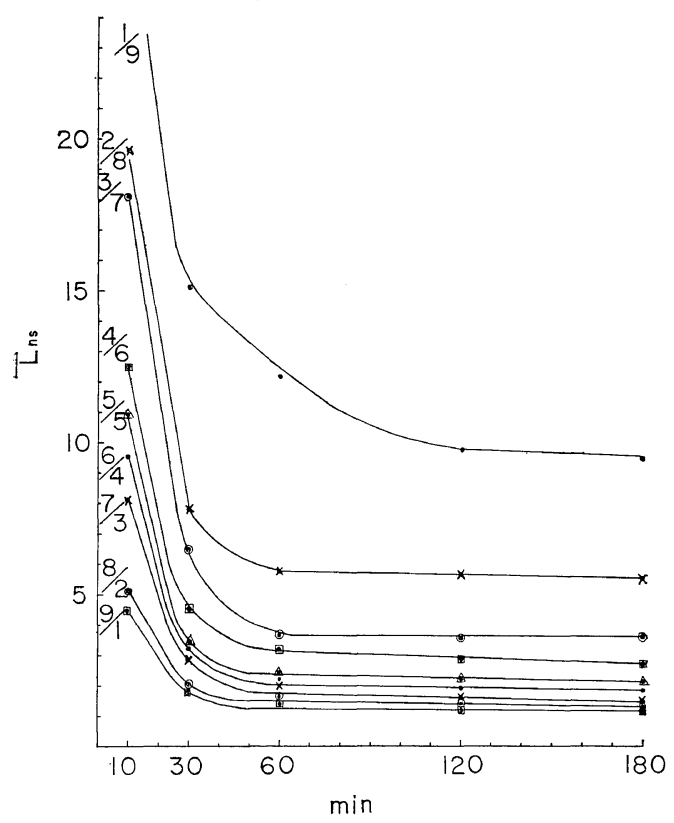

(b)

Figure 2. Changes of (a) $\bar{L}_{n T}$ and (b) $\bar{L}_{n S}$ during the transesterification reaction.
Reaction (c) proceeds by ester interchange between the hydroxyl group of a 2-hydroxyethyl ester end group and an ester linkage of an ethylene diester group along a polymer chain. As pointed out by Flory, ${ }^{6}$ reaction (b) can be expected to proceed at low rate, but cannot be ignored in the transesterification reaction between PET and PES. If we assume that hydroxyl groups of 2-hydroxyethyl ester end groups in PET and PES have the same reactivity, reaction (c) can be written as $\left(\mathrm{c}^{\prime}\right)$,

$\left(c^{\prime}\right) \sim \mathbf{T}-\mathbf{T} \cdots+\cdots \mathbf{S}-\mathbf{S} \sim 2 \underset{2}{2} \sim \mathbf{T}-\mathbf{S} \cdots$

This assumption seems to be quite reasonable from the fact that the (T-S) linkage increases by almost the same amounts in two samples having an inverse mole fraction of terephthalate and sebacate, i.e., $1 / 9$ and $9 / 1$ or $2 / 8$ and $8 / 2$, etc. (see Table I and Figure 1), and that $\bar{L}_{n T}$ and $\bar{L}_{n S}$ decrease in the same manner between these same samples, as shown in Figure 2.

Therefore the overall reaction of transesterification can be written as in eq 1 ,

$$
\sim \mathbf{S}-\mathbf{S} \sim+\cdots \mathbf{T}-\mathbf{T} \sim \underset{k^{\prime}}{\stackrel{k}{\rightleftarrows}} 2 \sim \mathbf{T}-\mathbf{S} \sim
$$

If the initial mole fractions of PET and PES are taken as $a$ and $b(a+b=1)$, and the mole fraction of the (T-S) linkage at time $t \mathrm{~min}$ is taken as $x$, the rate of the formation of $x$ can be expressed by eq 2, assuming the secondorder reaction.

$$
\frac{d x}{d t}=k\left(a-\frac{x}{2}\right)\left(b-\frac{x}{2}\right)-k^{\prime}\left(\frac{x}{2}\right)^{2}
$$

and taking $x_{e}$ as $x$ at equilibrium, eq 3 can be obtained.

$$
k\left(a-\frac{x_{e}}{2}\right)\left(b-\frac{x_{e}}{2}\right)-k^{\prime}\left(\frac{x_{e}}{2}\right)^{2}=0
$$

and eq 2 can be written as eq 4,

$$
\begin{array}{r}
\frac{d x}{d t}=k\left\{\left(a-\frac{x}{2}\right)\left(b-\frac{x}{2}\right)-\left(\frac{x}{2}\right)^{2}\right. \\
\left.\times \frac{\left(a-\frac{x_{e}}{2}\right)\left(b-\frac{x_{e}}{2}\right)}{\left(\frac{x_{e}}{2}\right)^{2}}\right\}
\end{array}
$$

The rate constant $k$ at time $t$ min can be obtained from eq 5 by integrating eq 4 ,

Polymer J., Vol. 2, No. 1, 1971 


$$
\begin{aligned}
& k t=\frac{1}{2 \sqrt{\left(\frac{a+b}{4}\right)^{2}-\frac{1}{4} a b\left\{1-\frac{\left(a-\frac{x_{e}}{2}\right)\left(b-\frac{x_{e}}{2}\right)}{\left(\frac{x_{e}}{2}\right)^{2}}\right\}}} \\
& \ln \frac{\frac{1}{4}\left\{1-\frac{\left(a-\frac{x_{e}}{2}\right)\left(b-\frac{x_{e}}{2}\right)}{\left(\frac{x_{e}}{2}\right)^{2}}\right\} x-\frac{a+b}{4}-\sqrt{\left(\frac{a+b}{4}\right)^{2}-\frac{1}{4} a b\left\{1-\frac{\left(a-\frac{x_{e}}{2}\right)\left(b-\frac{x_{e}}{2}\right)}{\left(\frac{x_{e}}{2}\right)^{2}}\right\}}}{\frac{1}{4}\left\{1-\frac{\left(a-\frac{x_{e}}{2}\right)\left(b-\frac{x_{e}}{2}\right)}{\left(\frac{x_{e}}{2}\right)^{2}}\right\} x-\frac{a+b}{4}+\sqrt{\left(\frac{a+b}{4}\right)^{2}-\frac{1}{4} a b\left\{1-\frac{\left(a-\frac{x_{e}}{2}\right)\left(b-\frac{x_{e}}{2}\right)}{\left(\frac{x_{e}}{2}\right)^{2}}\right\}}} . \\
& \times \frac{\frac{a+b}{4}-\sqrt{\left(\frac{a+b}{4}\right)^{2}-\frac{1}{4} a b\left\{1-\frac{\left(a-\frac{x_{e}}{2}\right)\left(b-\frac{x_{e}}{2}\right)}{\left(\frac{x_{e}}{2}\right)^{2}}\right\}}}{\frac{a+b}{4}+\sqrt{\left(\frac{a+b}{4}\right)^{2}-\frac{1}{4} a b\left\{1-\frac{\left(a-\frac{x_{e}}{2}\right)\left(b-\frac{x_{e}}{2}\right)}{\left(\frac{x_{e}}{2}\right)^{2}}\right\}}}
\end{aligned}
$$

Table II. Rate constants in transesterification reactions between PET and PES

\begin{tabular}{|c|c|c|c|c|}
\hline PET/PES & $\underset{\text { min }}{\text { Time }}$ & $\begin{array}{c}k^{\mathrm{a}}, \\
\mathrm{min}^{-1}\end{array}$ & $k / k^{\prime}-$ & $\begin{array}{l}k^{\prime a} \\
\text { min-1 }^{-1}\end{array}$ \\
\hline \multirow[t]{5}{*}{$4 / 6$} & 10 & 4.37 & & 7.38 \\
\hline & 30 & 5.54 & & 9.35 \\
\hline & 60 & 5.62 & & 9.49 \\
\hline & 120 & 4.22 & & 7.13 \\
\hline & 180 & 4.81 & 0.592 & 8.12 \\
\hline \multirow[t]{5}{*}{$3 / 7$} & 10 & 3.94 & & 5.98 \\
\hline & 30 & 4.70 & & 7.13 \\
\hline & 60 & 4.24 & & 6.43 \\
\hline & 120 & 5.56 & & 8.44 \\
\hline & 180 & 4.21 & 0.659 & 6.39 \\
\hline \multirow[t]{5}{*}{$2 / 8$} & 10 & 6.03 & & 9.63 \\
\hline & 30 & 5.93 & & 9.47 \\
\hline & 60 & 6.07 & & 9.67 \\
\hline & 120 & 5.50 & & 8.77 \\
\hline & 180 & 5.27 & 0.627 & 8.39 \\
\hline \multirow[t]{6}{*}{$1 / 9$} & 10 & 5.71 & & 8.60 \\
\hline & 30 & 5.61 & & 8.47 \\
\hline & 60 & 4.35 & & 6.56 \\
\hline & 120 & 4.33 & & 6.53 \\
\hline & 180 & 4.53 & 0.663 & 6.83 \\
\hline & \multicolumn{3}{|c|}{$4.92 \pm 0.770 .661 \pm 0.055$} & $7.50 \pm 1.29$ \\
\hline
\end{tabular}

\begin{tabular}{rrlll}
\hline PET/PES & $\begin{array}{c}\text { Time, } \\
\text { min }\end{array}$ & $\begin{array}{c}k^{\mathrm{a}}, \\
\mathrm{min}^{-1}\end{array}$ & $k / k^{\prime}$ & $\begin{array}{c}k^{\prime \mathrm{a}}, \\
\mathrm{min}^{-1}\end{array}$ \\
\hline $9 / 1$ & 10 & $5.77 \times 10^{-2}$ & $8.79 \times 10^{-2}$ \\
& 30 & 5.29 & & 8.07 \\
& 60 & 4.78 & & 7.29 \\
& 120 & 5.32 & & 8.12 \\
$8 / 2$ & 180 & 4.53 & 0.656 & 6.90 \\
& 10 & 6.12 & & 9.18 \\
& 30 & 5.75 & & 8.64 \\
& 60 & 5.32 & & 8.00 \\
& 120 & 4.69 & & 7.06 \\
& 180 & 5.20 & 0.665 & 7.82 \\
& 10 & 3.94 & & 5.83 \\
& 30 & 4.65 & & 6.87 \\
& 60 & 4.03 & & 5.98 \\
& 120 & 4.32 & & 6.38 \\
& 180 & 4.23 & 0.676 & 6.26 \\
& 10 & 3.56 & & 5.84 \\
& 30 & 4.81 & & 7.87 \\
& 60 & 5.53 & & 9.06 \\
& 120 & 4.53 & & 7.42 \\
& 180 & 4.03 & 0.611 & 6.58 \\
& 10 & 2.62 & & 3.28 \\
& 30 & 5.68 & & 7.12 \\
& 60 & 5.68 & & 7.12 \\
& 120 & 4.95 & & 6.20 \\
& 180 & 5.66 & 0.798 & 7.08 \\
& & & &
\end{tabular}

Table II. (continued) 


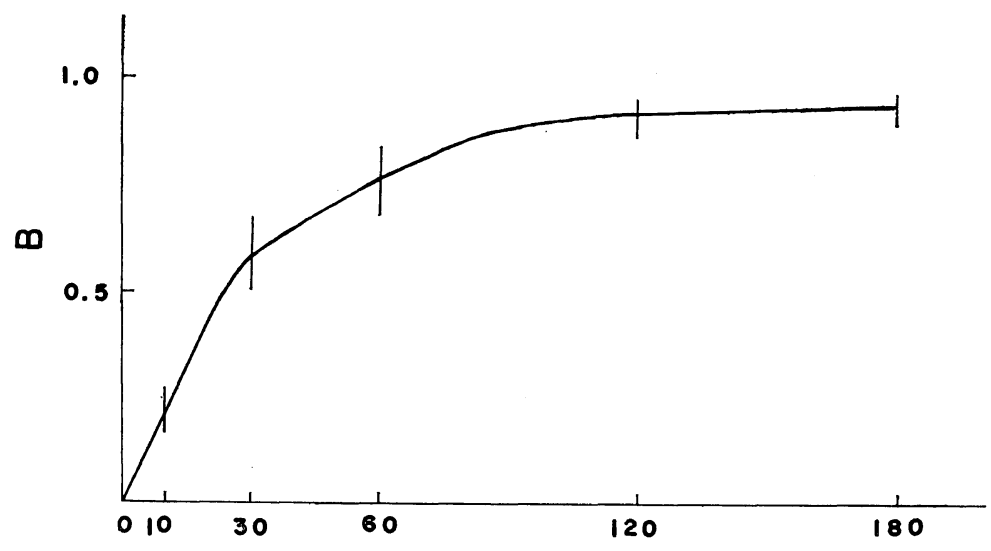

\section{Time (min)}

Figure 3. Changes in $B$ during the transesterification reaction between PET and PES.

Taking the values of $x$ at $t=180 \mathrm{~min}$ as $x_{e}$, values of $k$ were calculated by eq 5 and those of $k^{\prime}$ were obtained from eq 3 . These values are shown in Table II.

It seems reasonable to take the values of $x$ at $t=180 \mathrm{~min}$ as $x_{e}$, because as shown in Figure 2, $\bar{L}_{n T}$ and $\bar{L}_{n \mathrm{~S}}$ do not show any change at this point and the value of $B$ becomes constant at this time, as shown in Figure $3^{1}$.

As can be seen in Table II, $k$ and $k^{\prime}$ take almost constant values over all samples except in the initial stage of the reactions. This clearly shows that the transesterification reaction between PET and PES proceeds with a secondorder reaction (disregarding the order with respect to catalyst concentration.). Although $k$ takes nearly constant values at the initial stage of the reaction $(t=10 \mathrm{~min})$ in samples having greatly different feed ratios of PET and PES, such as $9 / 1,8 / 2,2 / 8$ or $1 / 9$, it takes quite small values in samples having the same feed ratio of PET and PES, i.e., 5/5. This is caused by the fact that in the former case one component can easily meet the other, but in the latter there is less probability that components will meet at that stage of the reaction. However they are mixed quite freely after $t=30 \mathrm{~min}$, and the value becomes constant after that.

\section{REFERENCES}

1. R. Yamadera and M. Murano, J. Polym. Sci., Part A-1 5, 2259 (1967).

2. T. Skwarski, Zeszyty Nauk. Politechn. Lodz. Chem., 4, (12) 41 (1956).

3. W. Griehl and G. Schnock, Faserforch. Textiltech., 8, 408 (1957).

4. G. Challa, Makromol. Chem., 38, 123 (1960).

5. C. M. Fontana, J. Polym. Sci., Part A-1, 6, 2343 (1968).

6. P. J. Flory, Chem. Reviews, 39, 137 (1946). 